\title{
An integral investigation into the phenomenology and neurophysiology of Christian Trinity meditation
}

\author{
Authors: \\ Stephen D. Edwards ${ }^{1}$ \\ David J. Edwards ${ }^{1}$

\section{Affiliations:} \\ ${ }^{1}$ Psychology Department, \\ University of Zululand, \\ South Africa

\section{Correspondence to:} \\ Stephen Edwards \\ Email: \\ sdedward@telkomsa.net \\ Postal address: \\ 3 Antigua, 32 Chartwell \\ Drive, Umhlanga Rocks 4319, \\ South Africa \\ Dates: \\ Received: 27 Mar. 2011 \\ Accepted: 19 Dec. 2011 \\ Published: 12 Mar. 2012 \\ How to cite this article: \\ Edwards, S.D. \& Edwards, \\ D.J., 2012, 'An integral \\ investigation into the \\ phenomenology and \\ neurophysiology of \\ Christian Trinity meditation', \\ HTS Teologiese Studies/ \\ Theological Studies 68(1), \\ \#Art. 1053, 9 pages. http:// \\ dx.doi.org/10.4102/hts. \\ v68i1.1053
}

C 2012. The Authors. Licensee: AOSIS OpenJournals. This work is licensed under the Creative Commons Attribution License.
This integral investigation explored phenomenological and neurophysiologic, individual and collective dimensions of Christian Trinitarian meditation experiences in a volunteer, convenience sample of 10 practicing Christians, 6 men and 4 women, with a mean age of 48 years and an age range from 21 to 85 years. Participants meditated for a minimum period of 15 minutes, during which neurophysiologic data in the form of electroencephalographic (EEG), electromyographic (EMG), blood volume pulse (BVP) and respiratory activity were recorded. A phenomenological analysis indicated that the meditation process generally involved a movement from body to mind to spirit as evident in reports of an increasingly relaxed, contented and focused state of consciousness characterised by Christian Trinitarian imagery, wonder, surrender, peace, bliss, openness and formlessness. The neuropsychological findings indicated significant increases, from baseline to meditation recordings, in the alpha and beta range, accompanied by increasing mean trends in the theta and gamma range, and decreasing mean trends in the delta range, EMG, BVP and respiration. Integrative findings indicated the practical theological value of small doses of Christian Trinity meditation to enhance spiritual life for those forms of waking, thinking, conscious behaviour needed in everyday world involvement and healing. Findings were discussed in relation to further integrative investigations and interventions with practical theological implications.

\section{Introduction}

From practical theological, integral, spiritual, individual, cultural, social and systemic perspectives, Christian prayer resembles other contemplative traditions such as Judaism, Hinduism, Taoism and Buddhism, especially in terms of meditative states and unfolding stages of image, metanoia, apathea, illumination and theosis (Chirban 1985:300-301; Wilber 2000). Similar to Islam, it has a specific historical, geographical and cultural context, grounded in the ancestral and theistic, spiritual and religious traditions of Africa and the Middle-East (Edwards 2009:81-83). The Christian Trinity embraces dimensional aspects of many spiritual traditions through recognition of a timeless, spaceless, ever-present, ultimately indescribable God and/or Godhead, as personally revealed through Jesus Christ, as well as an everyday practical guide in the form of the Holy Spirit. Despite perennial and inevitable misuse and misinterpretation through human destructives and bellicosity, as well as power and acquisitive motivations, the essential message of Christianity is one of Love, a message similar to that of many other spiritual and wisdom traditions.

This research was motivated by the spiritual needs to love, understand and share knowledge and experience in the form of individual and collective apprehensions, subjective and objective feelings and thoughts, as revealed, interpreted and explicated through Christian meditation, contemplation and/or prayer. Although the term 'contemplation' is used traditionally in Christianity, especially in relation to the reception of that blessing of Divine Presence, which is experienced after such practices as purification, confession and prayer, it was decided generally to use the term 'meditation', which occurs across other spiritual traditions as well as Christianity, for example, in centring prayer, which is practiced with a sacred word in silence (Keating 2009). The intention was to research that form of meditation that would both allow the disclosure of individual and collective apprehensions, common to Christianity and other spiritual traditions, as well as reveal universal and unique forms of meditation with everyday practical theological implications.

There are various forms of Christian contemplative and intercessory meditation and/or prayer. It was decided that meditation on the Trinity would be appropriate because, whilst aspects and dimensions of a triune concept are shared by other spiritual traditions, the apprehension of - and reverence for - the Holy Trinity is unique to Christianity. Similar to a Buddhist Koan, the Trinity concept is suitable for eliciting and/or generating various forms of irrational, pre- 
rational, rational and post-rational experiences, cognitions, reflections, interpretations and meanings. In short, the Trinity apprehension provides an ideal practical theological research theme for a single yet manifold, specific yet various, short or prolonged investigation into the form and/or formlessness of focused and/or varied sessions of contemplative and/or intercessory meditation and/or prayer.

In addition to Christian beliefs, theory and research, Wilber's (2000) all quadrants all levels (AQAL) model was chosen as a convenient theoretical framework to inform the design and methodology of the investigation. The AQAL model refers to a comprehensive system that integrates quadrants, levels, lines, states, types and realms of consciousness (Wilber 1997, 2000, 2007a). The AQAL approach postulates an essentially spiritual universe, composed of fundamental linkages called holons, which are always both wholes and parts of other wholes, in an ongoing process of evolution and involution, through a great nest of inter-being, transcending and including waves of consciousness experienced as matter, body, mind, soul and spirit. All holons have interior and exterior, as well as individual and collective perspectives. In the present study, the meditation experience is investigated from quantitative and qualitative, individual and collective, as well as subjective and objective perspectives.

The aim of the exploratory investigation was to discover and describe both individual and collective, and subjective and objective dimensions of Christian Trinitarian focused meditation, with special reference to the phenomenology and neurophysiology of these experiences. Whilst it was fully appreciated that any neurophysiologic correlates of such experiences would only provide simple material evidence of a phenomenology of experiences potentially reaching into vast spiritual realms, ultimately indescribable in terms of logic, language and numbers, it was considered that this data would provide valuable electrophysiological signatures of practical theological significance.

The qualitative research questions were as follows: What individual and collective phenomena are experienced, described and recorded during Trinitarian meditation? What are the essential structures of these phenomena? How do these relate to other spiritual traditions? The central quantitative research question related to various neurophysiologic correlates recorded during the Trinitarian meditation experience. In view of the fact that the Trinitarian meditation might elicit confusion, as well as infinite possible individual interpretations, it was predicted in null hypothesis form that any neurophysiologic data recorded would not differ significantly from data recorded during a prior period of rest. Finally, it was expected that some meaningful description of the Trinitarian meditative experience would emerge through phenomenological and neurophysiologic analyses and that integration of all data gathered would have valuable practical theological implications.

\section{Method Approach}

The AQAL approach provided a convenient and flexible triangulation framework for differentiating various research designs, methods and techniques (Wilber 1997, 2000, 2001). In its simplest form, the AQAL system distinguishes and integrates levels of consciousness along interior and exterior quadrants of the individual and collective. By its very nature, Trinity meditation involves different levels of consciousness such as body, mind and spirit. In the present study design, the four quadrants were represented by individual, collective, subjective phenomenological and objective neurophysiologic descriptions and recordings of Christian Trinity meditation experiences. These four quadrants may be collapsed conveniently into the first, second and third person, or ' $\mathrm{I}$ ', ' $w \mathrm{e}^{\prime}$ and 'it' perspectives, with ' $\mathrm{I}$ ' representing the upper left quadrant, 'we' the bottom left quadrant and 'it' or 'its' representing the upper and lower right quadrants, respectively.

\section{Paradigms}

Wilber (2001) has pointed out two meanings of the term 'paradigm', as originally intended by Kuhn (1962). The first refers to its usual usage as a body of theory or worldview which directs the general quest for knowledge, inquiry and/ or research. The second, more specific meaning specifies the practice of this quest, which includes three phases, (1) an instrumental injunction, which directs some actual practice, action or deed undertaken by the researcher, (2) an intuitive apprehension, direct experience or resultant data discovery and (3) communal confirmation or rejection of the data, which typically involves researcher decisions as to future action needing to be taken. This may be summarised conveniently as a 'do, discover and decide' sequence of typical scientific inquiry.

Wilber's AQAL approach is based on an integral philosophy of science and a post-metaphysical, post-postmodern epistemology, which leads to an integral methodological pluralism (Wilber 2007a) that transcends and includes supposedly theoretically disparate paradigms, in the broader meaning of this term as a perspective or collection of theories such as positivism or phenomenology. This epistemological approach becomes possible if it is accepted that the same investigative sequence, the same three deep strands of science - as implied in the specific meaning of the term 'paradigm' run through all such perspectives. This also enables research investigations to integrate knowledge specific to various domains, such as matter, mind and spirit, as well as recognise logical category errors that occur if knowledge derived from one domain is confused with, or substituted for, knowledge from another domain.

Both abovementioned meanings of the term 'paradigm' provided direction for the research design of this study. As a body of theory, there are three main paradigms in 
Human Science research, namely interpretive, positivistic and constructivist (Terre Blanche, Durrheim \& Painter 2006). The first two are represented in this study. The interpretive paradigm is represented by the first person, phenomenological analysis of participants' individual descriptions into natural meaning units of experience, individual and collective profiles. Positivism, which is based on an objective, ordered, causal, measurable view of the universe, is represented in the quantitative, neurophysiologic approach and resultant empirical, individual and collective data.

The actual investigation in the present study is a typical example of the second specific 'do, discover and decide' sequential meaning of paradigm. As co-researchers, both authors were reflexively involved in this sequence at both micro-levels and macro-levels of the process. The micro-levels involved personal, subjective Trinity meditation experiences and descriptions, whilst macro-levels involved discussion and objective analysis of the qualitative, quantitative and integrative findings, until stages of saturation and consensus were reached.

\section{Participants}

The 10 participants were all practicing Christians, who constituted a volunteer convenience sample, specifically chosen for their knowledge, experience, insight, commitment and willingness to explore, articulate, explicate and share their Trinitarian meditative experiences. The first five participants were all members of a Christian Protestant Church to which the authors belong. The remaining five participants volunteered out of interest in the project. There were six men and four women, with a mean age of 48.4 years and an age range from 21 to 85 years.

\section{Ethical considerations}

All participants were informed as to the nature of the research and provided their consent with regard to the use of the information for practical theological purposes. Participants were guaranteed nominal confidentiality and advised as to their right to withdraw from the research at any stage.

\section{Design}

A mixed, quantitative, qualitative and integrative design was adopted. The qualitative research methodology involved phenomenological analysis of natural meaning units of experience, individual and collective profiles supplemented by content analysis. The quantitative research methodology involved a within-group, repeated measures design and appropriate non-parametric statistics for the small, conveniently selected non-representative sample of participants.

\section{Procedure}

Seven of the ten participants' investigations took place in quiet and convenient conditions. The last three participants volunteered to meditate during an Infiniti Biofeedback Training Conference in which the first author was a guest speaker. Following the attachment of a biofeedback recording apparatus, the following standardised neurophysiologic recording instructions were put to all participants:

- Pre-test condition: Please rest for two minutes. You may keep your eyes open or closed, so long as you remain still and maintain a steady posture.

- Meditation condition: Please meditate on the Trinity. Feel free to explore any feeling, thought, person, relationship or context in relation to your past and/or present experience of the Trinity. Please try to experience or apprehend this moment, event or situation as immediately, directly, fully and deeply as possible.

Each individual assessment that lasted at least 15 minutes, the minimum length of time usually recommended for an effective meditation and/or contemplation session (Iyengar 2005; Keating 2009; Reid 1998), after which each participant briefly recorded his or her individual experiences of the meditation. These descriptions provided the basis for shared, inter-subjective discussion.

\section{Apparatus}

An Infiniti Thought Technology biofeedback apparatus (Thought Technology Ltd., Montreal, Canada) was used to monitor and simultaneously record neurophysiologic data in the form of electroencephalographic (EEG), electromyographic (EMG), blood volume pulse (BVP) and respiratory activity, respectively.

\section{Data analysis}

The limited amount of qualitative data lent itself readily to both phenomenological and thematic content analysis. The small size of the non-representative sample and the withinsubjects repeated measures design indicated non-parametric statistical analysis, which included the Wilcoxon signed-rank test for the quantitative data (Edwards 2006; Giorgi 1970; Terre Blanche et al. 2006).

\section{Results \\ Qualitative findings}

Interpretive findings are described below in terms of phenomenological and content analyses of participants' individual experiences. As individual descriptions of experiences are already brief, and detailed interpretive profiles would be essentially repetitive, a brief interpretive summary is provided as introduction to each profile, which is then analysed into the smallest, naturally occurring meaning units (NMUs) of experience (represented by the numbers in parenthesis after each NMU). Individual profiles are followed by a more detailed collective profile, with an audit trail of NMUs. Although sometimes grammatically incorrect, verbatim descriptions are retained for their authenticity.

\section{Participants' individual experiences}

Participant A (male, 27 years): Meditation includes various living imagery of the Trinity as Three-in-One through Jesus' death on the cross and resurrection to continual presence as Light and Love: 
'I meditated on Jesus walking or being present (1) with the Holy Spirit outside or next to him (2) and God watching over (4), like a cloud (5) or a voice over or around him (6). Also, Jesus was on the cross (7) and God watching over (8), his Holy Spirit being inside of him (9) then exiting after he died (10). Jesus resurrected there with me throughout this experience (11), and all the time (12). He is light; this is the Holy Spirit in him (13). Then you can see this mass of light (14) and cannot see anything else except this light (15). Then Jesus is sitting there watching over me (16), his Holy Spirit with him (17) and God watching over (18), he is there (19) and he is also smiling (20), then normal expression, then smiling (21). Then we are flying (22). I am flying with the Trinity (23). My most wonderful specific experience of God the Father, Son and Holy Spirit was seeing Christ sitting at the end of my bed watching over me and being there with me (24). Day to day experiences of God the Father, Son and Holy Spirit being with me (25), watching over me (26), and speaking to me about the path which they would like me to follow (27). At times when they have wanted me to go a certain direction they have clearly revealed this to me (28) and I can feel this experience throughout my spiritual and physical consciousness (29). I can feel that the giving of love to others comes from the Holy Trinity and that they are working through me (30).'

Participant B (male, 60 years): Meditation moves through increasingly subtle experiences of light, love, openness and peace to waking consciousness:

'I tried to replicate my half-hour morning contemplation, which I had written down (1): I closed my eyes and settled into a 3:7 breathing pattern (2), which gradually receded into the background (3) with an increasingly subtle, omniscient experience of light and love (4), which, in turn, gradually receded into simple openness, emptiness, silence, peace and waking consciousness (5). During the light and love apprehension, I recalled a poem I had written describing a similar experience, which reads as follows (6):

"Let us love the Love,

That's been loving us,

Since the beginning,

Now and forever (7)."

The essential difference I experienced between the two contemplations was that my early morning session involves lying down, whereas the current session was seated (8).'

Participant C (female, 58 years): Meditation involves clearing the mind, before focusing on the Three Persons of the Trinity, first individually, then as a harmonious interconnected cause:

'I cleared my mind of thoughts so it was empty (1). Then I focused on God the Father, his power and might as creator of the whole universe and beginning of all time (2) - a creator, allpowerful being and also a loving father (3) - his power, might and timelessness (4). Then I focused on Jesus the Son (5) as suffering servant in obedience to his father (6) and his suffering for our sake (7), like a lamb being slaughtered (8), but also his compassion for people when on earth (9), non-judgmental (10), a helper (11) and healer (12). Then I focused on the Holy Spirit (13) and his indwelling to connect us with the Father and the Son (13), and to guide us (14), infilling of us every day (15), topping us up (16), to enable us for the day (17), to guide (18) and guard us (19). Then I focused on the Trinity as harmonious interconnected cause (20), ultimately as God in three persons (21).'

Participant D (male, 51 years): Meditation involves inner stillness, and Trinity contemplation was accompanied by white light:
'I came to a place of inner stillness fairly quickly (1), strove to absorb rather than get rid of the sounds and smell around (2), was aware of the presence of God through the sounds and the smells (3), and was mindful of Jesus in my heart (4) and the presence of the Holy Spirit throughout my body (5). I felt a deep peace and sense of security (6), mindful of the Father embracing me (7), acutely aware of my physical body, for example teeth and finger tips (8). I was not aware of the attachments to my body (9) and did not in any way feel distracted by them (10). I had a unity experience of a ball of white light being continually embraced by waves of light (11).'

Participant E (female, 85 years): The Christian meditation process and structure is described in terms of altered states of consciousness, contemplation and centring prayer using a sacred word mantra. Various benefits, skills and precautions are mentioned:

'After a twenty minute meditation one needs a minute rest (1) so the psyche can readjust and align all the altered levels of consciousness (2). In meditation we have a long way to go (3). It is the highest form of surrender (4). That is it. We become less judgemental (5). With centring there is an acquaintance with God as friend (6) who takes care of you (7) and all the hiccoughs in the world will not upset you (8). During meditation, the thoughts come and go (9), but you have to return to the sacred word (10) and consent to God's presence and action within you (11). You choose your mantra, any word you like (12) and repeat that mantra over and over again (13). One needs to remember the three ' $r$ 's when thoughts come (14) - retain, don't resist and return to your sacred word and mantra (15). Let thoughts come and go (16), but keep returning to your sacred word (17) so the psyche can readjust to external sources (18). With much contemplation, one becomes a better person (19). When you get uptight, you say welcome to anything that upsets you (20). Over twenty years of meditation have changed my life completely (21). It has always been Christian-orientated as influenced by Keating, The cloud of unknowing and Saint Teresa of Avila (22). I also remember KISS keep it straight and simple (23). I was taught by Trappist monks (24). I get thoughts on the Trinity all the time through my sacred word which is Jesus (25). I feel energised (26), feel good (27). One must not meditate in the middle of the night as one will not sleep well then (28). When you come back to Jesus all feels good (29).'

Participant F (male, 21 years): After struggling with the structure, process and content of the meditation, improvements come through focus on posture, breath and Trinity repetition:

'Initially I did not know how to do it (1), that is, what was the purpose (2)? What I should be meditating about (3)? Unless faced by a catalyst, naturally occurring from life, I do not know how to initiate things sometimes (4). That was my primary difficulty (5). Initially I tried instigating by discussing what exists in the Trinity (6) and I daren't go beyond my satiated, in the moment, sense of firm faith and acknowledgement (7). The second time my posture was different (8) and I focused on my breathing (9) and repeated "One God, Triune Father, Son and Holy Spirit" (10).'

Participant G (female, 50 years): Meditation experiences include formlessness, colour and source imagery apprehensions:

'I have a sense of being wrapped in the love of God (1) and becoming weightless (2) and formless (3) as I sink into the embrace (4). I see that I am bathed in golden light (5) that has a 
vivid blue vibrating centre (6) and that I am part of all this (7). I feel content (8) and blissful (9) and know that I am loved (10) and that I love (11). I know that this is the place from which I have come (12).'

Participant H (male, 53 years): Meditation focuses on the three Persons of the Trinity from both individual and integrative perspective. Distractions are also mentioned:

'My meditation included the Father as all there is at all levels (1), the Son as the awareness which allows all knowing (2) and the Holy Spirit of animating energy as in breath (3). The sum of the three is: being, knowing and feeling (4) without a sense of personal identity (5) [...] a deep abiding silence (5). The session was very disturbed by a zzzzing in the room, lots of "high frequencies" (6). It is best to do this first thing in the morning (7).'

Participant I (female, 32 years): Difficulties and wonders of the meditation process are described:

'I found it difficult to get into a meditative state (1) as I was tired after a long day of much information (2). I did relax as time went on though (3). I also found it hard to stay focused on the Trinity itself (4) and not let my mind wander onto the church and my experiences with the church and people in it (5). When focused though (6), I do feel a sense of wonder regarding the Trinity (7) and what it means for me [...] love, grace and mercy (8). It is one of the most difficult things to comprehend though - Three-inOne (9) [...] and sometimes I find myself having a more cognitive view and comprehension than a feeling (10).'

Participant J (male, 47 years): Meditation concentration difficulties and solutions are described:

'I find it difficult to concentrate on the Trinity (1). As a result I just went back to saying the Jesus prayer (2): "Lord Jesus Christ have mercy on me" (3). I also meditated using prayer beads (4), which was done with the right hand on the same side as the mysoscan sensor (5).'

\section{Participants' collective experience}

The Trinity meditation's main collective experiential theme centred on the actual meditation process, which was described in terms of eye closure, breath pattern, focused concentration, posture, mantra, repetition, silence, stillness, presence, being, knowing, feeling, meaning, centring, and contemplation, in an increasingly relaxed and focused state of consciousness, characterised by imagery, consent, surrender, contentment, peace, wonder, bliss, formlessness, openness and emptiness (A24, B1-5, C1-2, D1, E10-19, F8-10, G1-12, H4, I6-8, J1-2). This process generally involved a movement from body to mind to spirit, for example, with body represented in consciousness of sounds, smells (D3) and breath patterns (B2, F9), mind represented by imagery (A1-23), thoughts and mantra (E9-18), soul and spirit represented by experiences of light, love, openness, emptiness, peace and silence (A13-15, B3-6, D11, G6-12, I8). During the meditation process some participants described struggles with concentration, focus and distraction (F1-7, H6, I1-5, J1).

Appropriately, the main phenomenological content of the collective experience was of God as Trinity or Three-in-One (A1-30, C20, F10, H4, 19), whose essence is Light (A13-15, B4, D11, G5) and Love (A, B, G, I). This was accompanied by views distinguishing the three Persons of the Trinity, God as Father (A24, C2, D7, F10, H1), Son Jesus (A24, C5, D4, E25, J2) and Holy Spirit (A9, C13, D5, F10, H3). This analysis of collective experience was supported by simple thematic content analysis, which revealed the following rank-ordered themes and their frequencies in parenthesis: God (16), Jesus (13), watching over me (13), consciousness (11), love (10), Holy Spirit (9), light (8), timelessness (8), Trinity (7), power (5), crucifixion (3) flying (3), smiling (2), working through me (2).

\section{Quantitative findings}

Quantitative findings are presented in the following tables and text. Data were coded for participants $(\mathrm{P})$, age in years, sex as male (M) or female (F), blood volume pulse (BVP) in mean number of beats per minute, muscle tension or relaxation as measured on an electromyograph (EMG) in $\mathrm{Hz}$ (cycles per second), respiration (RES) in terms of mean number of complete breath cycles per minute and electroencephalographic (EEG) activity in terms of percentage delta activity $(0 \mathrm{~Hz}-3 \mathrm{~Hz})$, theta activity $(4 \mathrm{~Hz}-7 \mathrm{~Hz})$, alpha activity $(8 \mathrm{~Hz}-12 \mathrm{~Hz})$ beta activity $(13 \mathrm{~Hz}-30 \mathrm{~Hz})$ and gamma activity $(>30 \mathrm{~Hz})$. In Table 1 numerical data are rounded off to the nearest whole number for space purposes.

Nonparametric analysis of this data indicated no significant differences within or between individuals for any of the variables in Table 1. Group differences were also all nonsignificant, except for findings from the Wilcoxon signedrank test for related variables. This revealed significant within-group effects for alpha and beta activities at the $1 \%$ and 5\% level respectively, which are indicated in Table 2 in terms of the standard scientific convention of double and single asterisks, respectively. Inspection of Table 2 facilitates the interpretation of these significant findings.

Table 2 indicates significant increases, from baseline to meditation recordings, in alpha activity: $Z(2,8)=2.70$, $p \leq 0.007$, and beta activity: $Z(2,8)=1.99, p \leq 0.047$, as well as increasing mean trends in theta and gamma activities and decreasing mean trends in delta activity, EMG, BVP and respiration. Taken collectively, these findings indicate that the null hypothesis of no significant differences should be rejected in favour of an alternative, working research hypothesis that the brief Trinity meditation experience of 15 minutes is associated with a form of relaxed, pleasant and alert state of waking consciousness. However, whilst the number of participants is very small and the sample nonrepresentative and therefore any interpretation of findings should be treated with caution, results are similar to those from other forms of meditation research (Iyengar 2005; Reid 1998; Shankar 2006; Travis \& Pearson 2000; Travis et al. 2005). Moreover, the findings support the practical theological value of small 15 minute doses of Christian Trinity meditation to 'top up' one's spiritual life for 'normal' forms of waking, thinking conscious behaviour needed in everyday world involvement and healing. 


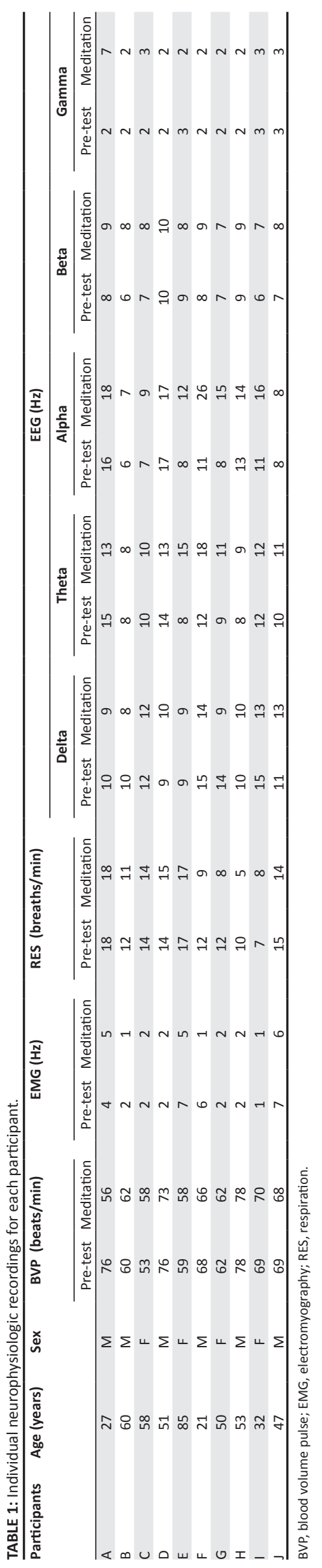

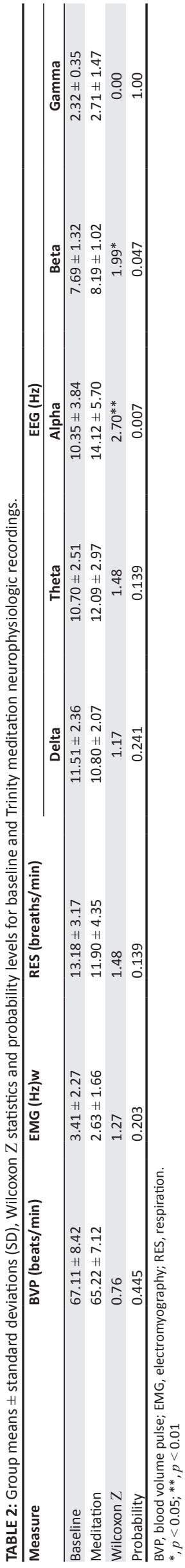

\section{Discussion}

\section{Practical theological implications}

The value and relevance of an integral, transpersonal approach in practical theology has recently received increasing recognition, especially with regard to pastoral counselling (Ferreira 2009; Sutherland 2001; Woodward \& Patterson 2000). The AQAL approach at least ensures that attention is given to individual and collective, subjective and objective perspectives on different levels of consciousness. In the present study, individual and collective analyses of both the phenomenological descriptions and the neurophysiologic recordings guaranteed subjective and objective perspectives on the different levels of consciousness experienced by the participants during Christian Trinity meditation.

Participant A's closing statement: 'I can feel that the giving of love to others comes from the Holy Trinity and that they working through $\mathrm{me}^{\prime}$ has particularly valuable practical theological implications. It is an example of a spiritual insight, peak experience or therapeutic moment that occurs in meditation, contemplation and other similar consciousness transformation practices that are recognised for their value in effecting healing of individuals, society and the wider environment (Corsini 1989; Ivey et al. 2002; Rogers 1980; Wilber, 1977, 2000, 2007a). Recent pastoral psychological evidence particularly points to the efficacy of such mystical insights in promoting mental health, meaning and purpose in life (Drazenovich \& Kourie 2010).

Participant E's protocol, which provides an outstanding individual example of collective quadrant and level trends, also implies a subtle distinction between spiritual gifts earned and those received, as traditionally associated with practices of meditation and contemplation, respectively. From an integrative perspective, individual and collective experiences indicate that Christian Trinity meditation is associated generally with an increasingly relaxed, contented, peaceful and focused state of consciousness, characterised by imagery, consent, surrender, wonder, bliss, openness and formlessness or emptiness. Such experiences are known to be related to increased alpha wave activity, as evident in the neurological recordings, as well as lowered physiological arousal, indicated by decreasing trends in pulse rate, muscle tension and respiratory activity (Ivey et al. 2002). Furthermore, the associated significant increases in beta activity, as well as related theta and gamma trends, support interpretations of both a relaxed and focused state of consciousness.

This becomes particularly understandable if the paradoxical nature of the Trinity is taken into account when viewed alternatively from mental and spiritual perspectives. For example, from a rational point of view, it is illogical for three distinct persons to be one at the same time and place. Yet, this is precisely what is experienced directly from a faith or spiritual perspective. It seems likely that the significant beta and alpha findings actually reflect this paradox, if beta and gamma are considered to be associated with alert, 
rational waking consciousness and alpha and theta related to those loosened cognitive constructs associated with more relaxed, dreamy states that occur during transformations of consciousness from the realm of rational mind to that of subtle soul and causal spirit.

In order to clarify such transformations from one level to another, Wilber (2001) has evoked St Bonaventure's insightful distinction between the eye of flesh, the eye of reason and the eye of contemplation. Bonaventure found the distinction valuable in clarifying various forms of illumination respectively: sensual (lumen exterius and inferius), mental (lumen interius) and spiritual (lumen superius). These forms were valuable in distinguishing between empirical cognition, as in seeking facts of the material world (cogitatio), seeking intuitive truths such as the image of God within the psyche (meditatio) and that transcendent insight apprehended when the soul unites with Godhead (contemplatio). Wilber (2001:3) has referred to the resulting object knowledge domains of matter, mind and spirit as sensibilia, intelligibilia and transcendelia; he noted that similar ideas can be found in every major school of traditional philosophy, psychology and religion, many of which are reviewed and integrated in his books (Wilber 2000, 2001, 2007a).

It would be very interesting in future to record longer, deeper and/or higher Trinity meditation experiences in order to investigate possible relationships between delta activity (characterised by a very low frequency of 0-3 cycles per second) usually associated with deep sleep and also possibly with the Godhead and/or formlessness apprehensions probably related to very subtle and/or causal levels of depth of consciousness experienced in meditation and contemplation respectively (Wilber 2007a). It would also be interesting to compare gamma activity (with a very high frequency of 40 or more cycles per second) in such investigations. When integrated with various other experiential and behavioural, subjective, inter-subjective and objective measures, focusing on such delta and gamma investigations may reveal interesting, associated apprehensions of higher and deeper levels of spiritual involvement in both immanent and/ or transcendent senses. As with other advanced spiritual practice, it can be predicted that this will have beneficial practical theological benefits at the personal, community and ecological levels. Such are the tasks and implications for future research investigations and interventions.

Future in-depth and longitudinal research is also needed to map accurately various transformations of consciousness that occur in both states and stages of Christian meditation and contemplation. The New Testament, especially John's Gospel of Jesus' statements regarding God's presence within him, and his place within God, is a prime resource, and the above-mentioned unfolding stages of image - metanoia, apathea, illumination and theosis - provide a valuable macroprocess baseline for such future investigations (Chirban 1985; Wilber 2000). Although such methods as Christian centring prayer are well established (Keating 2009), these tend to lack those precise stage, category or level distinctions apprehended, observed and consensually validated in Hindu and Buddhist traditions. Eastern Orthodox Christian approaches, as exemplified in the work of St Maximos, St Dionysis and St Basil, have made some headway in this regard (Chirban 1985). In addition to the New Testament, other resources include that vast body of experiential knowledge documented in Christian-orientated mystical traditions through such spiritual giants as St Augustine, St Bonaventure and Teilhard de Chardin, as well as by less recognised figures such as St John of the Cross, St Teresa and Eckhart (Huxley 1946; Wilber 2001, 2007a).

The AQAL theory postulates that all people develop through similar states and stages of consciousness. These may be mapped with what has become known as the WilberCoombs Lattice, in recognition of its two originators. Wilber (2007b) has provided the following Christian example, with colours of the spectrum differentiating different levels of consciousness:

Let's say a person has a peak experience of seeing a cloud of radiant white luminosity. Which at times appears as to be a person or being of light, and then has a sense of merging into that light, feeling a sense of infinite love and unbounded bliss. Let's say this person is a Protestant, whose lower left quadrant has predisposed his interpretations to see and clothe this experience in Christian terms. What will this person see? If he's at red altitude, he might see this as a magical Jesus who can walk on water, resurrect the dead, turn water into wine, multiply loaves and fishes, and so on. At amber, he might see Jesus as the eternal lawgiver, the bringer of complete salvation if one believes the myths and dogmas and follows the codes and commandments, and covenants given to the chosen people and found in the one and only true Book (the Bible). At orange, this person might see Jesus as a universal humanist, yet also divine, teaching world centric love and morality, and who can bring salvation not just in heaven but to some degree on this earth, in this life. At green, this person might see Jesus as one of many, equally valid spiritual teachers, and hence embracing Jesus might give complete salvation for me, which is why I passionately do so, but other individuals and cultures might find other spiritual paths to be better for them, knowing that all genuine spiritual paths, if they go deep enough, can offer an equal salvation or liberation. If this person is flying at turquoise, he might see Jesus as a manifestation of the same Christ-consciousness that everybody, including you and me, can have complete access to, and thus Jesus is emblematic of a transformative consciousness that shows each person to be part of a vast system of dynamic, flowing, and mutually interpenetrating processes that includes all of us in its radiant sweep. At violet and ultraviolet, Christ-consciousness might be seem as emblematic of the transcendental, infinite, selfless Self, the divine consciousness that was in Jesus and is in you and in me, a radically all-inclusive consciousness of Light, Love, and Life that is resurrected from the stream of time upon the death of the loveless and self-contracting ego, revealing a destiny beyond death, beyond suffering, beyond space and time and tears and terror, and hence found to be right here, right now, in the timeless moment in which all reality comes to be. (pp. 144-145)

Clearly such differentiated mapping of levels of consciousness with regard to any particular phenomenon will have great 
practical theological valuable in pastoral psychological situations, requiring empathically appropriate counselling. The present investigation is concerned essentially with Christian Trinity consciousness. It is also more concerned with what Porter (1999) has described as the Christ of faith rather than the Jesus of history. However, from an integral perspective, such consciousness is also essentially intersubjective, with historical, religious, cultural and contextual determinants. For example, it is important to understand that in the early Christian era, personhood 'was in some sense individual, but always in community as well' (Olson 1999:186) and it was in this context, in the third century after the birth of Jesus, that the Latin theologian, Tertullian, taught the unity of Father, Son and Holy Spirit as three persons in one Godhead. This, in turn, led to the First Council of Nicaea in the year 325, which established the Christian creed in terms of Father, Son and Holy Spirit with the following respective phrases regularly repeated in contexts of community prayer: 'one God, the Father', 'God of God, Light of Light, very God of very God, begotten, not made, being of one substance with the Father' and 'Holy Spirit, the Lord the giver of Life, who proceeds from the Father and the Son' (Church of the Province of South Africa 1989:108; Olson 1999). Clearly, such an historical, cultural and religious context, which is also reflected in the participants' descriptions, has an enormous role in maintaining and shaping Trinity consciousness and faith.

In this context, it should be noted that although the investigation honoured the basic requirements of the AQAL model, it was limited to very specific subjective, objective, individual and collective perspectives on different levels of consciousness. It should also be noted that the collective quadrants are derived rather than being primary in nature and that the general findings of this study should be viewed as very preliminary. Further quantitative and qualitative research involving both greater numbers of participants and in-depth exploration is needed, especially in relation to the collective quadrants. For example, the lower left, intersubjective, cultural quadrant could be investigated further through Trinity meditation focus group discussions. Similar focus group discussions could explore social systemic, interobjective comparisons with other spiritual and religious traditions in relation to Trinity conceptions in particular and meditation practices in general.

Further discussion on Trinity consciousness, especially in the second person, is relevant at this point. Based on extensive research into the known spiritual and religious traditions, Wilber (2007a) has distinguished what he refers to as first, second and third person perspectives or the 1,2 and 3 of God and/or Spirit, which have interesting parallels with the Christian Trinity. Third person perspectives refer to God as revealed through the awesome power of nature, as typified in the nature mysticism of Wordsworth's poetry. This traditional conception is also well represented as modern eco-systemic, Gaia and web-of-life theories, which run parallel with God as Father in the Christian Trinity. Second person perspectives include traditional theistic religions such as Judaism, Christianity and Islam, as typified in Martin Buber's 'I - Thou' relationship, in which 'Thou who is all Love' and 'to whom I surrender in love and devotion and sacrifice and release' (Wilber 2007a:159), as well as in deity mysticism, divine humanity and Jesus' original message of Love. First person perspectives are included in many meditation traditions, for example, the Witness, AtmanBrahman, Absolute Subjectivity, Spirit, Ultimate Source and Original Self found in causal and non-dual mysticism, Holy Spirit revelations and other mystical Christian Trinity apprehensions.

In conclusion, Wilber (2007a) notes the great value of a harmonious and balanced integration of all three perspectives of God and points out that the trend in new spiritual and religious movements of over-emphasising first and third person perspectives of God to the neglect of second person perspectives. The findings of the present study seem to address issues related to both the harmony of perspectives as well as the Divine Other. The integrated phenomenological and neurophysiologic evidence indicates that participants found the integral investigation into Trinity meditation practically and theologically valuable and meaningful. This is not surprising, considering the long-established value of such transformations of consciousness and behaviour that occur in and through meditative, contemplative and/or intercessory prayer and related spiritual practices in Christianity, as well as in many other theistic and non-theistic spiritual, wisdom and healing traditions, such as ancestor reverence, Judaism, Hinduism, Buddhism, Taoism and Islam.

\section{Acknowledgements}

This work is based on research supported by the University of Zululand and the South African National Research Foundation (NRF). Any opinion, finding and conclusion or recommendation expressed in this material is that of the author(s) and the NRF does not accept any liability in regard thereto.

\section{Competing interests}

The authors declare that they have no financial or personal relationship(s) which may have inappropriately influenced them in writing this article.

\section{Authors' contributions}

As co-researchers, S.D.E (University of Zululand) and D.J.E. (University of Zululand) took equal responsibility for the research and writing of this article, with the primary author S.D.E. conducting most of the work.

\section{References}

Chirban, J., 1985, 'Development stages in Eastern Orthodox Christianity', in K. Wilber J. Engler \& D.P. Brown (eds.), Transformations of consciousness: Conventional and contemplative perspectives ondevelopment, pp. 285-314, Shambhala, Boston, MA. 
Church of the Province of South Africa, 1989, An Anglican prayer book, Collins, London.

Corsini, R.J., 1989, Current psychotherapies, F.E. Peacock, Itasca, IL.

Drazenovich, G. \& Kourie, C., 2010, 'Mysticism and mental health: A critical dialogue', HTS Teologiese Studies/Theological Studies 66(2), 1-8.

Edwards, S.D., 2006, 'Experiencing the meaning of breathing', Indo-Pacific Journal of Phenomenology 6(1), 1-13.

Edwards, S.D., 2009, 'A breath-based apprehension of the Holy Spirit: practical theological, psychological, phenomenological and contextual perspectives', Practical Theology 24(2), 81-98.

Ferreira, I.W., 2009, 'Die ontwikkeling van die menslike bewussyn: Ken Wilber se AQAL-teorie', HTS Teologiese Studies/Theological Studies 66(1), 1-8.

Giorgi, A., 1970, Psychology as a human science: A phenomenologically based approach, Harper and Row, New York, NY.

Huxley, A., 1946, The perennial philosophy, Fontana, London.

Ivey, A.E., D’ Andrea, M., Ivey, M.B. \& Simek Morgan, L., 2002, Theories of counselling and psychotherapy: A multicultural perspective, Allyn and Bacon, Boston, MA.

Iyengar, B.K.S., 2005, Light on life, Rodale, London.

Keating, T., 2009, Intimacy with God: An introduction to centering prayer, Crossroads Publishing, NewYork, NY

Kuhn, T., 1962, The structure of scientific revolutions, University of Chicago Press, Chicago, IL.

Porter, J.R., 1999, The Jesus of history, the Christ of faith, Duncan Baird Publishers, London.

Reid, D., 1998, Chi-Gung: Harnessing the power of the universe, Simon and Schuster, London.
Rogers, C., 1980, A way of being, Houghton Mifflin, Boston, MA.

Shankar, G., 2006, Yoga psychotherapy and its applications, Satyam, New Delhi.

Sutherland, M., 2001, 'Developing a transpersonal approach to pastoral counselling', British Journal of Guidance and Counselling 29(4), 381-390. http://dx.doi. org $/ 10.1080 / 03069880120085938$

Terre Blanche, M., Durrheim, K. \& Painter, D., 2006, Research in practice: Applied methods for the socialsciences, University of Cape Town Press, Cape Town.

Travis, F. \& Pearson, C., 2000, 'Pure consciousness: Distinct phenomenological and physiological correlates of consciousnessitself', International Journal of Neuroscience 100, 77-89. http://dx.doi.org/10.3109/00207450008999678, PMid: 10512549

Travis, F., Munly, K., Olson, T.M. \& Sorflaten, J.W., 2005, 'Maharishi vedic science addresses the "hard" problem of consciousness', Journal of Social Behaviour and Personality 17, 123-135.

Wilber, K., 1977, The spectrum of consciousness, Quest, London.

Wilber, K., 1997, 'An integral theory of consciousness', Journal of Consciousness Studies 4(1), 71-92.

Wilber, K., 2000, Integral psychology, Shambhala, Boston.

Wilber, K., 2001, Eye to eye, Shambhala, Boston, MA.

Wilber, K., 2007a, Integral spirituality, Integral Books, Boston, MA.

Wilber, K., 2007b, The integral vision: A very short introduction to the revolutionary integral approach tolife, God, the universe, and everything, Shambhala, Boston, MA.

Woodward, J. \& Patterson, S., 2000, The Blackwell reader in pastoral and practical theology, Blackwell, Oxford. 